Check for updates

London

Cite this as: BMJ 2020;370:m3732 http://dx.doi.org/10.1136/bmj.m3732 Published: 25 September 2020

\section{Covid-19: Diagnosis of common conditions in general practice halved during lockdown, study finds}

\author{
Shaun Griffin
}

New diagnoses of mental health conditions, cardiovascular diseases, and type 2 diabetes approximately halved in Salford, Greater Manchester, during the country's covid-19 lockdown, a study has found.

Researchers used routinely collected primary care data recorded in the Salford Integrated Record system from 1 January 2010 to 31 May 2020. They then used computer modelling with monthly counts of first diagnoses of common conditions and corresponding first prescriptions of medicines to predict the expected numbers of each from 1 March to 31 May 2020, comparing them with the observed numbers.

They reported in the Lancet Public Health that the diagnoses of common mental health problems and type 2 diabetes halved during the first three months of lockdown (1073 reported $v 2147$ expected cases; $141 v 276$ ), and diagnoses of circulatory disease fell by $43 \%$ (598 reported $v 1054$ expected). The number of first prescriptions of associated medicines was also lower than expected over the period.

The $16 \%$ reduction between observed and expected cancer diagnoses (163 v 194) was not statistically significant. However, the hypothesis that this could be due to a relative lag in cancer diagnosis data being recorded in primary care was borne out by data from May, which revealed a $44 \%$ reduction in cancer diagnoses ( 38 observed $v 68$ expected), said the researchers.

The BMJ asked Richard Williams, lead investigator from the National Institute for Health Research's Greater Manchester Patient Safety Translational Research Centre, whether the results had changed since May. He said, "We now have a full six months of data, and although the observed diagnoses of type 2 diabetes and metformin prescriptions have crept back up and are now just inside what would be predicted for August, they are still significantly lower when you look at the whole six month period.

"None of the other diseases and medication have seen a recovery, and the observed values have continued to stay outside the predicted ones. Cancer continued to show large drops from May onwards, further supporting our hypothesis of recording delay."

\section{Prioritisation}

The findings mirrored recent data published by NHS England, which showed delayed waiting times throughout the NHS. ${ }^{2}$ "Delayed diagnosis and delayed waiting times is a perfect storm," said Williams. "How health services prioritise patients will be extremely important, especially in the face of the likely second wave."
The authors said that, as most of the conditions studied develop over the course of many years, it was unlikely that reduced incidences resulted from changed behaviours during the pandemic and "are most likely to represent a large number of true disease cases that have gone undetected, undiagnosed, and untreated."

Presentation rates could increase sharply when people begin to engage more with health services, the authors predicted. In this scenario, given the delay in diagnoses and the likely increased severity of these conditions when patients present, they suggested that "prioritisation over people with more minor illnesses will be important in primary care, otherwise the backlog could plausibly overwhelm primary and secondary healthcare services."

The authors called for national communication strategies to be carefully considered in advance of any future crisis, "to ensure that large numbers of patients with urgent health needs do not disengage with health services."

Williams R, Jenkins DA, Ashcroft DM, et al. Diagnosis of physical and mental health conditions in primary care during the COVID-19 pandemic: a retrospective cohort study. Lancet Publ Health 2020. doi: 10.1016/S2468-2667(20)30201-2. https://www.thelancet.com/journals/lanpub/article/PIIS2468-2667(20)30201-2/fulltext.

2 Griffin S. Covid-19: Waiting times in England reach record highs. BMJ 2020;370:m3557. doi: 10.1136/bmj.m3557 pmid: 32917660

This article is made freely available for use in accordance with BMJ's website terms and conditions for the duration of the covid-19 pandemic or until otherwise determined by BMJ. You may use, download and print the article for any lawful, non-commercial purpose (including text and data mining) provided that all copyright notices and trade marks are retained. 